\title{
Public and Private Sector Discount Rates in Public-Private Partnerships
}

\author{
Paul A Grout
}

CMPO, University of Bristol

September 2002

\begin{abstract}
Whether public sector projects should be discounted at a lower rate than private sector projects is a highly contentious issue and one that has spawned an enormous literature. The purpose of this paper is to assess the appropriate private and public sector discount rates in the context of public private partnerships. It is shown that there are powerful arguments for using a higher rate to discount private projects than public sector projects and that failure to recognise this may lead to excessive reliance on public provision. It is important to emphasise, however, that the reason for the divergence is not related to the conventional arguments of incomplete markets or taxation. Finally, we suggest that the results may have far broader implications for private sector involvement in public services.
\end{abstract}

JEL Classification: $\mathrm{H} 43$

Keywords: Discount Rates, Public-Private Partnerships

\section{Acknowledgements}

This paper was given at a CMPO session of the Royal Economic Society Conference 2002 (University of Warwick) on 'The Private Delivery of Public Services'. It is forthcoming in the Economic Journal (2003). This paper has als o benefited from comments at seminars at the University of Brunel, University of Manchester, HM Treasury (UK) and the Projects International Conference, 2001, Paris.

\author{
Address for Correspondence \\ Department of Economics \\ University of Bristol \\ 12 Priory Road \\ Bristol \\ BS8 1TN \\ Tel: +44 (0)1179289844 \\ p.a.grout@bristol.ac.uk
}




\section{Introduction}

In the last twenty years there has been a major increase in the role of the private sector in the delivery of what were once considered public sector services. Outside of transition economies, probably the single most significant change has been the international wave of privatisation of utilities. Such privatisations typically involve the complete transfer of ownership to the private sector with the role of the state being reduced to policing prices and conduct. More recently, however, there has been a rapid growth in more complex forms of private involvement. In many cases the public sector or its agencies remain the immediate final purchaser of the services but no longer own or operate the assets necessary for the provision of the service. Such arrangements tend to be referred to as public-private partnerships (PPP). In a typical PPP the government signs a long-term contract with a private consortium to supply a service to the government and the private consortium designs, builds, owns and runs the physical assets required for the delivery of the service. This contrasts with traditional public sector provision where the government builds or purchases physical assets, retains ownership and uses public sector employees or a private contractor to deliver the required service. A PPP can be characterised as a situation where the government becomes a purchaser of services not physical assets. ${ }^{1}$ This type of arrangement is now common in the case of roads, prisons, hospitals and schools both in the UK and elsewhere. ${ }^{2}$

\footnotetext{
${ }^{1}$ There are many complex forms of PPPs and the characterisation here focuses on the most basic model.

${ }^{2}$ For example, in the US alone there are 151 privately built prisons and the leader in the private management of public 'contract' schools has over 136 schools under contract. In many countries, including Canada and the UK, air traffic control is privately owned and run.
} 
The economic justification for PPPs is that they increase efficiency by aligning the incentives of the parties. ${ }^{3}$ As a result the government is able to provide the service at lower cost than would be possible with conventional public sector delivery. Indeed, the standard test criterion for a PPP project is that the cost to the government is less with a PPP than with conventional public provision. Clearly, this assessment is sensitive to the rate used to discount the cost of public provision and PPP. Of particular concern is whether the discount rate used to assess public provision should be the same as that used to assess a PPP. Whether public sector projects should be discounted at a lower rate than private sector projects is a highly contentious issue and one that has spawned an enormous literature. Writing in the eighties on public sector discount rates and their relation to private sector discount rates Lind pointed out that 'the profession was no closer to agreement on the theory, on a procedure for computing the discount rate, or on the rate itself than it was in $1966{ }^{\prime}{ }^{4}$ Despite this lack of unanimity there is a tendency for economists to favour the use of similar discount rates in the idealised situation of complete markets. Similarly, there is tendency for governments to use the same discount rate for a project whether it is publicly provided or is to be provided to the government by the private sector. For example, in the UK the rate of $6 \%$ real is used to discount and compare the cost of public provision with a PPP alternative.

The purpose of this paper is to assess the appropriate discount rates for PPP and public projects. It is shown that there are powerful arguments for using a higher rate to discount private projects than public sector projects. It is important to emphasise,

\footnotetext{
${ }^{3}$ There are several theoretical papers that address the efficiency of PPPs, notably, Bennett and Iossa (2002), Bentz, Grout and Halonen (2002) and Hart (2002) (see also Hart, Schleifer and Vishny (1997)). See Grout (1997) for an assessment of the private finance initiative.

${ }^{4}$ Lind (1982).
} 
however, that the reason for the divergence between private sector and public sector discount rates is not related to the normal arguments given in the literature. Even in a world of complete capital markets and no distortionary taxation it may still appropriate to use a higher discount rate for the PPP than the public sector equivalent.

\section{Public and private discount rates}

\subsection{Introduction}

As indicated in the introduction the view that the public sector should discount projects at the same rate as the private sector is not without controversy. ${ }^{5}$ A large literature developed on this topic in the 1960s and 1970s and several contributors (see, for example, Arrow (1965,1966), Arrow and Lind (1970), Samuelson (1964), Solow (1965) and Vickrey (1964)) took the view that public sector rates should be lower because the public sector can pool risks. These views have been criticised, notably by Bailey and Jensen (1972), Diamond (1967) and Hirshleifer (1964), who have pointed out that the arguments that the private sector cannot pool risks are not theoretically sound and that the nature of risks in the public sector are unlikely to satisfy the Arrow and Lind requirement that the outcomes of public projects are independent of each other and of private investments. ${ }^{6}$ Putting to one side adjustments that may be necessary because of taxation (see Baumol (1968), Sandmo and Dreze (1971) and Harberger (1968)), if there are complete markets then projects should be spanned by existing securities and so, at least theoretically, individuals should be able to divest themselves of their risks at market prices whether these arise in the public or private

\footnotetext{
${ }^{5}$ Note, one common argument used is that the public sector can borrow at far lower rates. This, however, clearly relates to the default rate not the nature of differences in risk between public sector and private sector projects and is a obviously a false justification for any difference in discount rates. ${ }^{6}$ See Lind (1982) for a detailed discussion of discount rates in the private and public sectors and Brealey, Cooper and Habib (1997) for an excellent summary of the issues.
} 
sector. This would appear to indicate that arguments for using higher discount rates for private projects must rest with imperfections in markets.

\subsection{Finance tests for PPPs}

A feature of assessment procedures for public private partnerships is that the central test is one of cost minimisation to the public sector for a specified standard of service. In this respect it differs from conventional cost benefit test approaches that have traditionally been advocated and often employed in other areas of public provision. Here we outline when a pure finance test and a cost benefit test provide the same answer. This has important implications for the debate on public versus private sector discount rates.

Consider a public service project that can be conducted fully in the public sector or with a PPP. It is helpful to focus the discussion if one thinks of a specific example of a road that will have zero charges to the public at the point of use. With public provision a public sector agency can either built the road itself directly or can engage a contractor to build the road for the agency. The government will then own the road and undertake its upkeep. Within a PPP the private sector will build, own and maintain the road and the government's role is to enter into a contract to pay for a the flow of services to the public. A standard model is one where the government makes a payment to the private owner for each vehicle that uses the road.

In each case the project delivers a flow of benefits, $v_{t}(g)$ and $v_{t}(p)$, and costs, $c_{t}(g)$ and $c_{t}(p)$, where $p, g$ and $t$ denote PPP, public sector and time respectively. A cost benefit test would opt for public provision if

$$
\int_{0}^{\infty} v_{t}(g) e^{-r_{i}(g) t} d t-\int_{0}^{\infty} c_{t}(g) e^{-r_{c}(g) t} d t>\int_{0}^{\infty} v_{t}(p) e^{-r_{v}(p) t} d t-\int_{0}^{\infty} c_{t}(p) e^{-r_{c}(p) t} d t
$$


and the PPP if the inequality in (1) is reversed, where $r_{v}(i)$ and $r_{c}(i)$ are the discount rates for benefits and costs, $i=p, g$.

In contrast a pure finance base test compares the cost to the government of public provision with the cost to the public sector of conducting the project as a PPP. The financial cost to the government of public provision is the cost stream that the public sector has to fund:

$$
\int_{0}^{\infty} c_{t}(g) e^{-r t} d t
$$

where $\mathrm{r}$ is the discount rate used by the government in the pure finance test. Within a PPP the government has to fund the present value of the service specified in the contract. That is, service quantity, $\mathrm{q}_{\mathrm{t}}$, is measured and the private sector is funded according to the agreed price, $p_{t}$ per unit. The financial cost to the government of the PPP is

$$
\int_{0}^{\infty} p_{t} q_{t} e^{-r t} d t
$$

Using this pure finance test, public provision is preferred if

$$
\int_{0}^{\infty} c_{t}(g) e^{-r t} d t<\int_{0}^{\infty} p_{t} q_{t} e^{-r t} d t
$$

and the PPP is preferred if the inequality is reversed.

The following proposition shows when these two are equivalent. 
Proposition: The pure finance test is equivalent to a full cost benefit test if the

following hold .

$$
\begin{aligned}
& \text { (i) } \int_{0}^{\infty} p_{t} q_{i} e^{-r t} d t=\int_{0}^{\infty} c_{t}(p) e^{-r_{c}(p) t} d t \\
& \text { (ii) } \mathrm{V}_{t}(g)=\mathrm{V}_{t}(p) \\
& \text { (iii) } r_{j}(g)=r_{j}(p) \quad, \quad j=\mathrm{v}, \mathrm{c} \\
& \text { (iv) } \quad r=r_{c}(p)
\end{aligned}
$$

The result follows straightforwardly. If (i) holds then (1) becomes:

$$
\begin{aligned}
& \int_{0}^{\infty} v_{t}(g) e^{-r(g) t} d t-\int_{0}^{\infty} c_{t}(g) e^{-r_{c}(g) t} d t \\
& >\int_{0}^{\infty} v_{t}(p) e^{-r(p) t} d t-\int_{0}^{\infty} p_{t} q_{t} e^{-r t} d t
\end{aligned}
$$

and if (ii) and (iii) hold then this reduces to

$$
\int_{0}^{\infty} p_{t} q_{t} e^{-r t} d t>\int_{0}^{\infty} c_{t}(g) e^{-r c(p) t} d t
$$

Finally, if (iv) holds then (1) is equivalent to (4).

If all four conditions hold then each of the conditions in the proposition has a natural interpretation. (i) is a restriction on competition. It only holds if the competition between the potential private sector partners for the PPP is such that there are no ex ante excess profits. (ii) is a requirement on public and private benefits; stating that the quantity and quality of benefits is the same in the public project and the PPP. While this is unlikely to be the case in practice it is perfectly possible in theory to adjust the pure finance test to incorporate differences in quality. (iii) and (iv) relate to public and private sector discount rates. (iii) states that the appropriate rate to discount the 
benefits (costs) should be the same whether the project is public or a PPP. In the context of the discussion in 2.1, (iii) does not seem an unrealistic requirement. However (iv) is a far more powerful assumption since it requires the single discount rate used in the finance test to be equal to the discount rate that is appropriate for the cost stream in the PPP. The following section is given over to showing that in this is unlikely to be a sensible assumption and discusses the implications for public and private sector discount rates.

\subsection{Implications for public and private sector discount rates.}

Condition (iv) states that the single discount rates used in the financial test should be equal to the discount rate that is appropriate for the private sector's cost stream. It is tempting, but incorrect, to fall back onto the discussion given in subsection 2.1 to believe that the use of a single discount rate equal to private sector discount rate for costs is an innocuous assumption. Again it is helpful to interpret the financial test in terms of the road example. This shows clearly that the choice of a single public and private sector discount rate in the pure finance test cannot rely on the conventional argument.

The discount rate used for public sector provision is applied to the cost cash flow $c_{t}(g)$. This is the cash flow that represents the cost of building the road if it is built in the public sector. In contrast, the discount rate used for the private sector provision is applied to $p_{t} q_{t}$. This is not the equivalent cost of building the road with a PPP. It is the cash flow associated with the flow of benefits valued at the price in the contract. 
There is no reason to suppose that the risk characteristics are equivalent for these two cash flows; indeed there is every reason to suppose that they are not.

It is instructive to look at a special, albeit realistic, case to elucidate the point. This is where we restrict attention to the case where aggregate demand for the project is independent of the allocation of income within the community and the government uses a linear reimbursement schedule. The attraction of the former restriction is that in this case even if the choice of public or private provision affects income distribution, there will be no effect on aggregate demand. Aggregate demand is independent of the distribution of income if the indirect utility function can be characterised by the Gorman polar form. The Gorman polar form implies that the demand for a good must be of the form:

$$
q_{i}=a_{i}(\underline{p})+b(\underline{p}) m_{i}
$$

where $i$ denotes the consumer and $p$ the vector of prices in the economy. In this case the revenue for the PPP can be represented:

$$
R=p \Sigma_{i} a_{i}(\underline{p})+p b(\underline{p}) \Sigma_{i} m_{i}
$$

(where $\mathrm{p}$ is the price in the PPP contract) and the costs can be represented:

$$
C=c \Sigma_{i} a_{i}(\underline{p})+c b(\underline{p}) \Sigma_{i} m_{i}+F
$$

where $\mathrm{F}$ is the fixed component of cost.

Using the Gorman polar form and a linear payment schedule we can explicitly calculate the risk characteristics of these cash flows as measured by their beta (the 
weighted covariance between the cash flow and aggregate income). It is easy to show that the $\beta$ for the revenue cash flow is:

$$
\beta_{R}=\frac{\operatorname{cov}(R, m)}{\operatorname{var}(m)}=\frac{\sigma_{R}}{\sigma_{m}}=p \Sigma_{i} b(\underline{p})
$$

and the $\beta$ for the cost stream is

$$
\beta_{C}=\frac{\operatorname{cov}(C, m)}{\operatorname{var}(m)}=\frac{\sigma_{c}}{\sigma_{m}}=c \Sigma_{i} b(\underline{p})
$$

where $\mathrm{m}=\Sigma_{i} m_{i}$

Thus the ratio of the betas is equal to the ratio of price to marginal cost.

$$
\frac{\beta_{R}}{\beta_{C}}=\frac{\text { price }}{\text { marginal cost }}
$$

There are two reasons to expect the price per unit in the PPP contract to be greater than the marginal cost. One is that fixed costs associated with PPP projects tend to be large. Again thinking of the road example, the marginal cost per vehicle is likely to be extremely small relative to the payment per vehicle to the partnership since the latter has to be sufficiently high to recoup the cost of building the road over the life of the contract. Hence the price-marginal cost ratio may be very large. The second reason is that economic theory predicts that an optimal incentive scheme is almost certain to require the supplier to bear some of the risk of supply. Assuming that there are hidden actions, the harder it is to contract over quality and the greater the relationship between usage and quality then the more high powered the incentive scheme ought to be. Linear schemes of this sort are quite common in practice. 
Theoretically, it is unlikely that the exact payment scheme should be linear but in certain circumstances there are justifications for linearity (See Hart and Holström (1987) and Holström and Milgrom (1987)). The general point, however, does not depend on this precise specification; we should expect to see a significant divergence between the private sector discount rates used to discount revenues and costs within a PPP.

Turning to the relevant discount rate for the public sector then it is clear from 2.2 that it is the cost stream that is discounted. In general, the public sector cost in the comparison should not be discounted at the same rate as the private sector costs. That is, the relevant beta for the public sector component of a pure finance test should be that given by (9) and the relevant beta for the PPP should be that given by (8).

\section{Conclusion}

This paper has argued that the standard practice of using similar discount rates for private and public provision in tests between public sector and PPPs is inappropriate. We have argued that lower discount rates should be used for the public sector than the private sector. Failure to do so will suggest that private provision is less efficient than public since the present value of private provision will be overestimated relative to public. It is important to emphasise, however, that the reason for the divergence between private sector and public sector discount rates is not related to the normal arguments in the literature. Even in a world of complete capital markets and no distortionary taxation it is still appropriate to use a higher discount rate for the PPP than the public sector equivalent. This is a consequence of comparing the costs to the 
government of the two alternatives. This difference would disappear if the government chose to assess PPP by their costs of construction and maintenance not the cost of the contract for providing services to the public sector. Clearly, there are good reasons why this does not happen but the consequences for discount rates needs to be recognised.

This paper has focussed specifically on financial test for PPPs. However, the problem that we have identified is likely to be far more general. The cash flows that are discounted by state treasuries around the world tend to be cost cash flows in the sense that we are using them in this article. In contrast, any private contribution to the provision of services, when viewed by the government, tends to have some elements of revenue or net revenues built in. It follows that, although it may be legitimate to use the same rate for exact comparisons of similar cash flows between private and public sectors, in many instances the assessment procedures for private involvement in public services justifies the use of separate discount rates for the two sectors. Failure to recognise this is likely to prejudice private provision and favour too much public sector provision. 


\section{References}

Arrow, K. (1965). 'Criteria for Social Investment', Water Resources Research, vol. 1, pp. 1-8.

Arrow, K. (1966). 'Discounting and Public Investment Criteria', in (A. V. Kneese and S. C. Smith, eds), Water Research, Baltimore, MD: Johns Hopkins University Press.

Arrow, K. and Lind, R. C. (1970). 'Uncertainty and the Evaluation of Public Investment Decisions', American Economic Review, vol. 60, pp. 364-78.

Bailey, M. J. and Jensen, M. C. (1972). 'Risk and the Discount Rate for Public Investment', in (M. C. Jensen, ed.), Studies in the Theory of Capital Markets, New York, NY: Frederick A Praeger.

Baumol, W. J. (1968). 'On the Social Rate of Discount', American Economic Review, vol. 58, pp. 788-802.

Bennett, J. and Iossa, E. (2002). 'Building and Managing Facilities for Public Services', Working Paper no. 02-08, Brunel University.

Bentz, A., Grout, P. A. and Halonen, M. (2002). 'What Should the State Buy?', Working Paper no. 01/040, Centre for Market and Public Organisation.

Brealey, R. A., Cooper, I. A., and Habib, M. A. (1997). 'Investment Appraisal in the Public Sector', Oxford Review of Economic Policy, vol. 13, pp. 12-28.

Diamond, P. A. (1967). 'The Role of Stock Market in a General Equilibrium Model with Technological Uncertainty', American Economic Review, vol. 57, pp. 75976.

Grout, P. A. (1997). 'The Economics of the Private Finance Initiative', Oxford Review of Economic Policy, vol. 13, pp. 53-66.

Harberger, A. C. (1968). 'On Measuring the Social Opportunity Cost of Public Funds', in Proceedings of the Committee on Water Resources and Economic Development of the West; The Discount Rate in Public Investment Evaluation, Denver, CO: Western Agricultural Economics Research Council.

Hart, O. (2002). 'Incomplete Contracts and Public Ownership: Remarks and an Application to Public-Private Partnerships', presented at the RES Conference, 2002, University of Warwick.

Hart, O. and Holström, B. (1987). 'The Theory of Contracts', in (T. F. Bewley ed.), Advances in Economic Theory. Cambridge: Cambridge University Press 
Hart, O., Shleifer, A. and Vishny, R. W. (1997). 'The Proper Scope of Government: Theory and an Application to Prisons', Quarterly Journal of Economics, vol. 112, pp. 1126-61.

Hirshleifer, J. (1964). 'Efficient Allocation of Capital in an Uncertain World', American Economic Review, vol. 54, pp. 77-85.

Holström, B. and Milgrom, P. (1987). 'Aggregation and Linearity in the Provision of Intertemporal Incentives’, Econometrica, vol. 55, pp. 303-328.

Lind, R. C. (ed.) (1982). Discounting for Time and Risk in Energy Policy. Baltimore: Johns Hopkins Press.

Samuelson, P. A. (1964). 'Principals of Efficiency: Discussion', American Economic Review, vol. 81, pp. 191-209.

Sandmo, A. and Drèze, J. H. (1971). 'Discount Rates for Public Investment in Closed and Open Economies', Economica, vol. 38, pp. 395-412.

Solow, R. M. (1965). Capital Theory and the Rate of Return. Chicago, IL: Rand McNally.

Vickrey, W. (1964). 'Principals of Efficie ncy: Discussion', American Economic Review, vol. 54, pp. 88-92. 